Revisión blibliográfica

Volumen 32(2):662-680. Mayo-agosto, 2021 e-ISSN 2215-3608, doi:10.15517/am.v32i2.40628

https://revistas.ucr.ac.cr/index.php/agromeso/index

\title{
Biotecnología aplicada al estudio de la movilidad del semen porcino ${ }^{1}$
}

\section{Applied biotechnology to the study of the boar semen motility}

\author{
Anthony Valverde ${ }^{2}$, Vinicio Barquero², Vanesa Carvajal ${ }^{3}$
}

1 Recepción: 11 de marzo, 2020. Aceptación: 3 de agosto, 2020. Este trabajo formó parte del proyecto de investigación 5402-2151-1015, inscrito en la Vicerrectoría de Investigación y Extensión del Instituto Tecnológico de Costa Rica (ITCR), San Carlos, Costa Rica.

2 Instituto Tecnológico de Costa Rica (ITCR), Escuela de Agronomía, Centro de Investigación y Desarrollo en Agricultura Sostenible del Trópico Húmedo, Campus Tecnológico Local San Carlos. Apdo. Postal 223-21002 Alajuela, Costa Rica. anvalverde@ tec.ac.cr (autor para la correspondencia; https://orcid.org/0000-0002-3191-6965), vinicio1196@gmail.com (https://orcid.org/0000-0003-0042-6178).

3 Instituto Tecnológico de Costa Rica (ITCR), Escuela de Ciencias Naturales y Exactas. Campus Tecnológico Local San Carlos. Apdo. Postal 223-21002 Alajuela, Costa Rica. vcarvajal@tec.ac.cr (https://orcid.org/0000-0003-2166-1716).

\section{Resumen}

Introducción. El uso de biotecnologías reproductivas ha significado una mejora relevante sobre los parámetros de eficiencia y rentabilidad en la industria porcina. Objetivo. Determinar el estado del arte en el que se encuentra la biotecnología aplicada al estudio del semen y la implementación; en granjas porcinas; de técnicas de reproducción asistida como la inseminación artificial. Desarrollo. En el sector porcino, la fertilidad de los verracos (Sus scrofa domestica) tiene un efecto significativo sobre la eficiencia general de la reproducción de las piaras. Aunque hay métodos objetivos de valoración precisa de las variables seminales de los verracos, muchas granjas aún continúan realizando sus evaluaciones de forma subjetiva. Los conceptos bioquímicos que determinan la funcionalidad del gameto masculino o espermatozoide son molecularmente complejos, sin embargo, pueden conocerse los aspectos generales de la funcionalidad y desarrollar métodos de manejo del semen que permita el mantenimiento de las condiciones óptimas de las muestras seminales o dosis de semen utilizadas en inseminación artificial (IA). Dentro de la funcionalidad espermática intervienen parámetros clásicos de volumen, concentración y movilidad que son fundamentales para la optimización de las dosis seminales producidas por verraco. Los sistemas CASA (Computerassisted semen analysis) son una aplicación biotecnológica que desplaza el análisis subjetivo tradicional del semen para la valoración de la calidad, estos aportan grandes volúmenes de información que han permitido explorar más en detalle los eyaculados porcinos. Conclusiones. En las granjas que utilizan la inseminación artificial, el uso de técnicas biotecnológicas para el análisis seminal, constituye un valor agregado para el estudio de la calidad del semen y la optimización de dosis seminales producidas.

Palabras claves: eyaculado, reproducción, verraco, inseminación artificial.

\begin{abstract}
Introduction. The use of reproductive biotechnologies has meant an important improvement of the efficiency and profitability in the swine industry. Objective. To determine the state of the art in which the applied biotechnology to semen study and their implementation; in pig farms; of assisted reproductive techniques such as artificial insemination. Development. In the swine industry, the fertility of boars (Sus scrofa domestica) has a significant effect
\end{abstract}


on the overall efficiency of herd reproduction. Although there are objective methods of accurate assessment of the boar's semen variables, many farms still carry out subjectively assessments. The biochemical concepts that determine the functionality of the spermatozoa are molecularly complex, however, the general aspects of functionality can be known, and semen management methods can be developed that allow the maintenance of the optimal conditions of the semen doses used in artificial insemination (AI). Within the sperm functionality, classical parameters of volume, concentration, and motility are involved, which are fundamental for the optimization of the seminal doses produced by boar. The CASA (Computer-assisted semen analysis) systems are a biotechnological application that displaces the traditional subjective semen analysis and provides a large data that have allowed us to explore in greater detail the boar ejaculates. Conclusions. Biotechnological semen processes are a tool for assessing seminal quality and optimizing seminal doses on farms that use artificial insemination.

Keywords: ejaculate, reproduction, boar, artificial insemination.

\section{Introducción}

El manejo reproductivo es un factor fundamental en cualquier explotación ganadera. La selección de verracos (Sus scrofa domestica) con una fertilidad relativamente mayor es económicamente necesaria, tanto para los productores como para las empresas de venta de dosis seminales. Sin embargo, todavía no se dispone de variables precisas y objetivas para predecir con exactitud los resultados de fertilidad que se puedan obtener en las granjas. Existe una alta complejidad en los mecanismos moleculares que determinan las funciones de los espermatozoides de verraco y se hace complicado la descripción completa de los mecanismos involucrados.

Se reconocen tres mecanismos en la función espermática: fuentes de energía extracelular, utilización de la glucosa y la función mitocondrial como promotores de la movilidad espermática. La movilidad y la morfología son los indicadores más utilizados de la calidad del esperma y son los parámetros de rutina que se utilizan para la decisión de aprobación o rechazo de los eyaculados para su uso en inseminación artificial (IA) (Flowers, 1997; Kondracki et al., 2012). La movilidad se ha evaluado tradicional y subjetivamente mediante microscopía de contraste de fase, sin embargo, existe un análisis objetivo de semen asistido por computadora (CASA), disponible para evaluar las características de la movilidad de los espermatozoides (Amann \& Waberski, 2014). La ventaja de un análisis objetivo de la movilidad del semen, ha llevado a un mayor uso de los sistemas CASA para la evaluación de la calidad del esperma en mamíferos (Verstegen et al., 2002). Sin embargo, para utilizar el potencial del análisis de estos sistemas biotecnológicos en los centros de IA, es necesario realizar más estudios sobre las características específicas del movimiento de los espermatozoides dentro de los eyaculados y cómo estos se correlacionan con la fertilidad masculina.

El objetivo de esta revisión bibliográfica fue determinar el estado del arte en el que se encuentra la biotecnología aplicada al estudio del semen y la implementación; en granjas porcinas; de técnicas de reproducción asistida como la inseminación artificial.

\section{Método de obtención del eyaculado}

El desarrollo de técnicas para la obtención de los eyaculados en especies ganaderas, se llevó a cabo de forma simultánea con la inseminación artificial (Bonet et al., 2013) y constituye una condición obligatoria para las tecnologías seminales. Todos los métodos deben garantizar la calidad microbiológica (Althouse et al., 2000) y de variables espermáticas del semen obtenido (Tejerina et al., 2008). El semen se puede recuperar in vivo o post mortem. 
Los métodos in vivo tienen que ser inocuos para los animales, de fácil aplicación y los materiales utilizados deben ser de menor coste posible (Quirós-Rojas et al., 2018).

En la mayoría de las especies, para recuperar el semen in vivo se utilizan vaginas artificiales (Jiménez-Rabadán et al., 2012). Este dispositivo trata de simular artificialmente la estructura genital de la hembra, lo cual permite recolectar todo el eyaculado de forma limpia y se utiliza en la mayoría de las especies ganaderas (Naughton et al., 2003), con excepción de los verracos y gallos.

Para la recuperación del semen se pueden utilizar hembras que pueden estar en celo o no y maniquíes o potros de monta (Flowers, 2015). Debido a que el personal trabaja cerca del verraco, el corral debe estar diseñado para permitir múltiples sitios de escape fuera del corral si el animal se vuelve agresivo. Deben construirse dos o tres de los muros perimetrales con una tubería galvanizada de $5 \mathrm{~cm}$ de diámetro exterior. Esta tubería debe tener $1 \mathrm{~m}$ de altura y colocarse a intervalos de $0,3 \mathrm{~m}$ en el centro. La altura y el espacio (aproximadamente $0,25 \mathrm{~m}$ ) entre las tuberías, deben permitir que el personal ingrese y salga fácilmente del área de recolección sin tener que abrir o cerrar las puertas, pero restringir al verraco al área del corral. El ancho recomendado para este corral de recolección es de 1,8 a 2,4 m y un largo de 2,4 a 2,75 m (Tosky et al., 2013). El maniquí de recolección debe colocarse de forma estable en el corral para dicho fin. Las características adicionales de los maniquíes de colección pueden incluir la capacidad de ajuste de altura (esto es útil en verracos jóvenes) y algún tipo de soporte en los lados, que permitan al verraco estabilizar sus patas delanteras durante el montaje y el empuje. Debe proporcionarse una superficie antideslizante alrededor del maniquí, para que el verraco tenga una base segura durante el montaje y el empuje. El potro de colección se puede colocar en una esquina del corral de monta o con un extremo contra la pared, para que el verraco pueda dirigirse y mantenerse fácilmente alrededor del potro. El corral y el potro de colección deben ubicarse lejos de otros verracos y otras distracciones que desvíen la atención del verraco (Lopez-Rodriguez et al., 2017).

La edad a partir de la cual se puede iniciar los entrenamientos de los machos varía en función de la líneas genéticas y las condiciones de manejo en granja (Broekhuijse et al., 2012). La mayoría de los verracos utilizados para inseminación artificial comienzan su rendimiento reproductivo a la edad de 7-8 meses, y alcanzan capacidades de desarrollo y producción completas posteriormente (Banaszewska \& Kondracki, 2012), pero en general los verracos se empiezan a entrenar sobre los seis meses (Knecht et al., 2017).

La recuperación del material seminal en verracos parte de la premisa que esta especie eyacula por la presión que se ejerce sobre las espirales del pene, y el método que frecuentemente se utiliza recibe el nombre de la mano enguantada (Awda \& Buhr, 2008), en donde se usa doble guante para la obtención de la muestra (Valverde et al., 2019e). Durante el proceso, el verraco monta sobre un potro de colección o maniquí (Flowers, 2015), la frecuencia varía en función de la edad del animal. Aunque se han descrito frecuencias de dos recuperaciones/semana (Pruneda et al., 2005), este ritmo es muy intensivo para algunos verracos y son habituales frecuencias de recuperación menores (tres veces/dos semanas). Se ha descrito que una alta frecuencia de recolección tiene un efecto negativo sobre la morfología y la movilidad de los espermatozoides porque los espermatozoides, se ven obligados a pasar rápidamente por el epidídimo, por lo que no tienen tiempo suficiente para la maduración epididimaria (Strzežek et al., 1995). Los verracos recolectados dos veces al día durante cuatro días consecutivos, suelen presentar más gotas proximales, más anormalidades en la cabeza y la cola y menor movilidad que los verracos de control recolectados una vez cada dos días en el mismo período (Pruneda et al., 2005).

La recolección de semen ha sido identificada como el punto más crítico para la contaminación bacteriana (Goldberg et al., 2013). Previamente a la obtención del semen, debe limpiarse el divertículo prepucial para eliminar residuos de orina y posteriormente, se elimina el primer guante de la mano del técnico de manera tal que le queda el segundo guante para que realice el procedimiento de recuperación del semen. Se pueden usar guantes de polivinilo y deben evitarse los guantes de látex, ya que son tóxicos para los espermatozoides (Ko et al., 1989). El verraco presenta una eyaculación trifásica y tiene una duración que puede sobrepasar los veinte minutos. La primera parte del eyaculado $(\sim 25 \mathrm{ml}$; fase pre-espermática) debe descartarse porque presenta una concentración muy baja de 
espermatozoides y puede tener un alto recuento bacteriano (Goldberg et al., 2013). La segunda parte del eyaculado se le denomina fracción rica (Ratchamak et al., 2019) (40-100 ml), contiene entre 80 y $90 \%$ de todas las células de esperma en la eyaculación, corresponde a la fase que mayor concentración de espermatozoides y es la que se utiliza para criopreservar semen. La tercera parte del eyaculado es la fracción pobre en espermatozoides o post-espermática y es la que aporta mayor cantidad de plasma seminal. Esta fracción está compuesta principalmente por secreciones de las vesículas seminales, la próstata, glándulas de Cowper que actúan como un tope para el cuello del útero de la cerda en condiciones de monta natural y, hacia el final de la eyaculación, las glándulas bulbouretrales. Esta fase al final del eyaculado corresponde a una fracción gelatinosa que se le suele denominar tapioca, que se debe eliminar con el propósito de evitar una posible aglutinación de los espermatozoides (Herrick, 1950). Los recipientes de recolección contienen un vaso de precipitados en su interior, cubierto por un filtro que permite eliminar la tapioca.

Es importante mantener las precauciones respecto del manejo de los animales y del semen para no ocasionar estrés ni disminuir la calidad espermática. Durante la extracción de semen es necesario un conocimiento del comportamiento sexual de la especie. Se ha observado que la estimulación sexual previa de los machos, como la masturbación previa a montar el maniquí, aumenta la producción de semen (Levis \& Reicks, 2005). Esto tiene una base fisiológica, ya que el estímulo previo favorece que la neurohipófisis descargue oxitocina y esta actúa sobre la musculatura lisa que rodea a la cola del epidídimo, favoreciendo una movilización de las reservas hacia los conductos deferentes. Los verracos que tienen un estímulo sexual parecen completar la recolección más rápido, lo que resulta en una mayor cantidad de machos procesados en un periodo de tiempo menor. Además, estos verracos parecen tener un mayor conteo de espermatozoides (Levis \& Reicks, 2005).

La estimulación de los verracos con prostaglandinas ( $\mathrm{PGF}{ }_{\alpha}$ ) también se ha estudiado, sin embargo, aparte del resultado de reducir el tiempo de aparición del eyaculado y una mayor duración de la eyaculación, no se ha observado ningún efecto en la concentración espermática o la calidad del semen (Estienne \& Harper, 2004).

El proceso de obtención del eyaculado debe ser aséptico en todo momento, ya que al no mantener las condiciones higiénicas se provocará una contaminación bacteriana y viral del semen y, consecuentemente, de las dosis seminales (Althouse \& Lu, 2005). Además, el pelo que rodea la zona del orificio prepucial debe recortarse, porque podría provocar contaminación por bacterias (Althouse et al., 2000). En otras investigaciones se ha descrito que la contaminación por bacterias puede causar una disminución en la calidad del semen por los efectos directos de estas o por la acción indirecta de los subproductos bacterianos en los espermatozoides (Sepúlveda et al., 2014).

Se debe considerar que las instalaciones en donde se recupera el semen sean seguras para los verracos y los técnicos y debe permitir el procesamiento rápido y ágil de muchos verracos (Levis \& Reicks, 2005). Otros métodos que se han desarrollado, son los sistemas automatizados de recolección de semen, las cuales han demostrado que aumentan la cantidad de verracos procesados por colector por hora, sin disminuir la producción de semen en términos de concentración y volumen (Aneas et al., 2008).

El manejo del semen es fundamental para evitar choques térmicos en los espermatozoides de verraco. El enfriamiento rápido puede causar daños a los espermatozoides y, por lo tanto, se debe mantener su temperatura $\left(37-38^{\circ} \mathrm{C}\right.$ ) durante todo el proceso hasta la preparación de las dosis seminales que se almacenarán a $17^{\circ} \mathrm{C}$ (Maes et al., 2011). Para ello, es fundamental que el material de laboratorio y los equipos a utilizar estén atemperados a 37 ${ }^{\circ} \mathrm{C}$. Además, hay que evitar el contacto del semen con el agua y con la luz directa y hay que extremar las medidas de higiene durante el proceso de recuperación y manipulación posterior del semen.

\section{Factores que influyen en el metabolismo espermático}

El eyaculado contiene espermatozoides y plasma seminal (PS). El PS es una mezcla de fluidos provenientes de la región caudal del epidídimo y las glándulas sexuales accesorias (Davies et al., 1975). Además, el PS está 
relacionado con los procesos de capacitación espermática, y estimula el sistema inmune femenino, para eliminar patógenos y tolerar espermatozoides y embriones (Rodríguez-Martínez et al., 2011). La actividad de enzimas como la $\gamma$-glutamil-transferasa (GGT) o la fosfatasa alcalina (ALP), está relacionada con la calidad seminal y la función de la membrana, ambas participan en diferentes procesos metabólicos durante la maduración espermática (Seligman et al., 2005). En otros trabajos, se ha descrito una baja actividad de ALP en verracos azoospérmicos (Clements et al., 2010). En los verracos, algunos cambios en la composición mineral están relacionados con la estación y el estrés por calor (Murase et al., 2007).

El PS está compuesto por minerales como el zinc ( $\mathrm{Zn}$ ) o el selenio (Se). El selenio es un componente estructural de la glutatión peroxidasa (GPx), que protege las membranas celulares contra los efectos adversos de los peróxidos lipídicos (Pieczyńska \& Grajeta, 2015), preservando así la integridad estructural de la membrana plasmática de los espermatozoides (Wu et al., 1979). También se ha encontrado una correlación entre el Se y la preservación de la integridad de la membrana que se refleja en el aumento del adenosín trifosfato (ATP) en los espermatozoides, lo que lleva a mejorar el porcentaje de movilidad total y progresiva (Pipan et al., 2017). Se ha reportado que la espermatogénesis se puede ver afectada por deficiencia de Se en especies como el verraco (MarinGuzman et al., 2000), en donde se ha observado disminución de la concentración de ATP y aumento en el porcentaje de espermatozoides inmaduros en verracos alimentados con una dieta de bajo Se (Marin-Guzman et al., 2000). Niveles altos de Zn mejoran la función mitocondrial (Pipan et al., 2017).

En un estudio previo en verracos no se encontró una correlación entre el $\mathrm{Zn}$ en plasma seminal y las características de calidad espermática, pero se detectó una correlación negativa con las colas anormales (LópezRodríguez et al., 2013). El Zn puede proteger a los espermatozoides contra el estrés oxidativo (Colagar et al., 2009) y se considera un mejor conservador de la función mitocondrial, ya que las mitocondrias son el principal sitio de formación intracelular de especies reactivas de oxígeno (Guthrie et al., 2008). Tanto el selenio como el zinc se han asociado con la calidad del semen en humanos, debido a sus propiedades antioxidantes (Björndahl \& Kvist, 2009), aunque pueden ser dañinos por encima de ciertos niveles (Sağlam et al., 2015).

Sales inorgánicas como sodio $(\mathrm{Na})$, calcio $(\mathrm{Ca})$, magnesio $(\mathrm{Mg})$, cloro $(\mathrm{Cl})$ y potasio $(\mathrm{K})$, intervienen en el mantenimiento de la integridad de la membrana plasmática y la presión osmótica. Se ha demostrado que el potasio ayuda a conservar la movilidad de los espermatozoides y, por ello se agrega a varios diluyentes comerciales (Johnson et al., 2000). El sodio se correlaciona con la morfología normal de los espermatozoides (López-Rodríguez et al., 2013). Niveles elevados de hierro (Fe) se correlacionan con un mayor nivel de morfología espermática normal y espermatozoides vivos después del almacenamiento (Pipan et al., 2017). Debido a que los espermatozoides están sometidos a un mayor estrés oxidativo durante el almacenamiento (Kumaresan et al., 2009), los niveles bajos de Fe pueden conducir a una menor actividad de la enzimas Fe dependientes como por ejemplo, la catalasa (Massányi et al., 2003), lo que podría conllevar a un aumento de la peroxidación lipídica en los espermatozoides del verraco y reducir la viabilidad (Martinez-Alborcia et al., 2012).

El cobre $(\mathrm{Cu})$ es esencial para las enzimas como la superóxido dismutasa, que interviene en la protección de los espermatozoides contra los radicales libres de oxígeno (Leonhard-Marek, 2001), sin embargo, las concentraciones altas de $\mathrm{Cu}$ reducen la glucólisis, que podría explicar la disminución del potencial mitocondrial que se traduce en una disminución de la movilidad espermática (Pesch et al., 2006).

Los valores óptimos de movilidad de los espermatozoides indican el metabolismo activo y la integridad de las membranas (Johnson et al., 2000). Los diluyentes deben asegurar el mantenimiento de la movilidad y la viabilidad de los espermatozoides, mediante la amortiguación del pH para neutralizar los desechos metabólicos y la osmolalidad (Britt et al., 1999). Hay presencia de compuestos que actúan como buffer o soluciones tamponadas como el bicarbonato $\left(\mathrm{HCO}_{3}^{-}\right)$, que se encargan de regular el $\mathrm{pH}$ en unos límites adecuados. Por otro lado, en el semen hay sustratos energéticos como el sorbitol, que es un azúcar alcohólico que puede penetrar los espermatozoides (Buhr et al., 2001), la glicerilfosforilcolina o la fructosa, que son utilizadas para la producción de energía en condiciones de 
aerobiosis o anaerobiosis. Además, se ha descrito que la combinación de glucosa y fructosa sobre el medio mTALP (modified calcium-free Tyrode's Albumin Lactate Pyruvate) mejora la movilidad, las reacción del acrosoma y la tasa de penetración de los espermatozoides, lo que aumenta la capacidad de fertilización de los espermatozoides del verraco (Tsujii et al., 2006).

Durante la eyaculación, los espermatozoides entran en contacto con el plasma seminal, que contiene concentraciones más altas de $\mathrm{HCO}_{3}^{-}\left(\sim 20 \mathrm{mmol}^{-1} \mathrm{l}^{-1}\right)$ (Okamura et al., 1985), pero también factores decapacitantes, principalmente espermadhesinas de las glándulas sexuales accesorias, que recubren y estabilizan la superficie de los espermatozoides para prevenir la capacitación prematura (Töpfer-Petersen et al., 2009). A medida que avanzan en el útero hacia el oviducto, los espermatozoides tienen que nadar a través de varios entornos cada vez más ricos en $\mathrm{HCO}_{3}^{-}\left(\sim 25 \mathrm{mmol} \cdot \mathrm{l}^{-1}\right)$ (Hess et al., 2005) y los factores de incapacitación se eliminan gradualmente, lo que permite la desestabilización y la capacitación de la membrana.

En verracos, se ha propuesto que el plasma seminal puede ser sustituido por un medio de dilución sin un efecto perjudicial relevante, sin embargo, estudios han demostrado que el plasma seminal presenta diferentes funciones para el metabolismo de los espermatozoides (Rodríguez-Martínez et al., 2011); además, este contiene una alta concentración de inositol, así como de ergotioneina (en verracos y garañones) (Audet et al., 2004), L-glutatión y ácido L-ascórbico, que pueden ser responsables del potencial antioxidante del plasma seminal (Surai \& Fisinin, 2015). Adicionalmente, el plasma seminal contiene sustancias antimicrobianas (Ig A), hormonas (andrógenos, estrógenos, prostaglandinas), proteínas y vitaminas (ácido ascórbico o riboflavina) (Ledesma et al., 2017). Debido a que algunos constituyentes del plasma seminal son producidos específicamente por algunas glándulas sexuales, su análisis puede servir para diagnosticar problemas o disfuncionalidad en alguna estructura glandular en concreto (Rodríguez-Martínez et al., 2011).

La movilidad de los espermatozoides es ATP dependiente, sin embargo, el ATP también se requiere para el funcionamiento de las reacciones de la glucólisis y el ciclo de Krebs y para el mantenimiento del gradiente iónico de la membrana. Para suplir estos requerimientos energéticos, los espermatozoides utilizan principalmente sustratos extracelulares, y son capaces de metabolizar monosacáridos (fructosa o glucosa) y otros sustratos extracelulares como ácido láctico o aminoácidos. Se ha indicado una correlación positiva entre concentraciones de ATP en el semen y el porcentaje de células móviles totales y células progresivas. La interacción entre la concentración de ATP y la movilidad de los espermatozoides de verraco se ha explicado previamente por la cantidad de calcio en las células, que afecta la movilidad a través de la regulación de la concentración de ATP en la célula (Li et al., 2016). La pérdida de la movilidad puede deberse a una menor producción de ATP en las células y se ha observado una disminución en el ATP como resultado del almacenamiento en diferentes medios de dilución (Gogol et al., 2009). Esto respalda la hipótesis que indica que la disminución en el número de células móviles podría estar relacionada con la disminución en las concentraciones de ATP como resultado del almacenamiento de semen (Tremoen et al., 2018).

En condiciones de anaerobiosis, el espermatozoide utiliza fructosa o glucosa y mediante la glucólisis que tiene lugar en el citoplasma se genera piruvato y dos unidades de ATP (por cada fructosa o glucosa utilizada). Se ha sugerido que la glucólisis en la pieza principal es crítica para la función normal de los espermatozoides (Turner, 2003). Para que la glucólisis siga funcionando con normalidad en ausencia de oxígeno, el piruvato obtenido es convertido en ácido láctico mediante la fermentación láctica, generando en el proceso NAD+ (nicotinamida adenina dinucleótido), que se necesita como cofactor en algunas de las reacciones de la glucólisis. Hay especies cuyos espermatozoides tienen altas tasas de respiración y no pueden mantener la movilidad celular únicamente con la glucólisis (verraco, garañón), especies con alta respiración y glucólisis (bovinos) y otras con esperma que dependen principalmente de la glucólisis (humana) (Cummins, 2009). En aerobiosis, el piruvato obtenido mediante glicólisis es oxidado acetil coenzima A, la cual es degradada mediante el ciclo de Krebs (Medrano et al., 2006), en las mitocondrias, produciendo un balance neto de 36 ATP por cada unidad de glucosa o fructosa utilizada. Esta vía es más eficaz en la generación de energía que la ruta anaeróbica. 
Existen una serie de factores que modifican la tasa metabólica de los espermatozoides, algunos de ellos se utilizan como estrategias para prolongar el tiempo de vida útil. Los factores que modifican la tasa metabólica (Tourmente \& Roldan, 2015) de los espermatozoides son la temperatura (McPherson et al., 2014), el pH (Davies et al., 1975), la presión osmótica (Smith \& England, 2001), la concentración de espermatozoides (Valverde et al., 2019f), la luz (Lopez-Rodriguez et al., 2017) y algunos agentes antibacterianos (Maroto-Martín et al., 2010). La tasa metabólica de los espermatozoides es máxima a temperatura corporal, y disminuye cuando se reduce la temperatura. Cuanto más baja es la temperatura, menor es la tasa metabólica, pero en esos casos hay que evitar otros problemas como por ejemplo, el choque térmico. Si se producen alteraciones del pH se reduce la tasa metabólica, pero también la fertilidad de los espermatozoides, por ello, es importante tamponar los medios (Knox, 2016). La concentración de ATP es directamente proporcional a la tasa metabólica (Tourmente \& Roldan, 2015), la cual se asocia positivamente con la velocidad espermática. Además, se ha observado que la testosterona inhibe el metabolismo espermático (Lelono et al., 2019), mientras que los fluidos del sistema reproductor femenino estimulan el metabolismo (de Catanzaro \& Pollock, 2016). Otros componentes que inhiben el metabolismo son el dióxido de carbono a una concentración de 5-10 \%, así como la luz, que además afecta a la fertilidad.

La energía para el funcionamiento del gameto masculino proviene de dos fuentes: externas y de las reservas intracelulares. Los principales mecanismos de producción de energía a partir de fuentes externas que presentan los espermatozoides de los mamíferos, se basan en el procesamiento de monosacáridos a través de la vía glucolítica y la posterior metabolización a través de la fosforilación oxidativa mitocondrial (Rodríguez-Gil \& Bonet, 2016). Por otro lado, la principal vía de producción de energía de las reservas internas será la degradación de los depósitos de glucógeno en glucosa, que luego se procesará en glucólisis y, eventualmente, la posterior fosforilación oxidativa mitocondrial. Existen otras fuentes de energía disponibles para los espermatozoides, por lo tanto, los metabolitos extracelulares como el lactato, el piruvato, el citrato, el glicerol e incluso los triglicéridos, se han informado como fuentes de energía externas para los espermatozoides de verraco (Jones \& Bubb, 2000). Sin embargo, es necesario el estudio de estos metabolitos como importantes fuentes de energía y un mayor conocimiento sobre el uso de metabolitos no azucarados en la función espermática.

\section{Valoración del semen}

La evaluación de la calidad seminal es importante por motivos de carácter económico (Houška et al., 2004), debido al gran impacto que tiene el macho en la eficacia reproductiva (Robinson \& Buhr, 2005) de las granjas, desde que se utiliza como rutina la inseminación artificial. Por eso, es importante el manejo reproductivo adecuado de los machos y la eliminación de aquellos animales o eyaculados que presentan baja fertilidad. Además, es necesario disponer de técnicas adecuadas para valorar la calidad del semen que haya sido sometido a diversos procedimientos como, por ejemplo, la crioconservación (Ratchamak et al., 2019).

La calidad del semen se puede evaluar in vivo o in vitro. Con los métodos in vivo se conoce la fertilidad real de las dosis, pero las pruebas en campo son muy costosas y, además, los resultados no son inmediatos, por lo que se requiere tiempo para hacer los diagnósticos de gestación para determinar si las hembras han quedado preñadas o el tamaño de camada en especies politocas. Por esta razón, se han desarrollado métodos de valoración del semen in vitro; estos métodos son considerablemente más baratos que las pruebas in vivo $\mathrm{y}$, además, los resultados se obtienen más rápidamente. No obstante, los métodos in vitro estiman la calidad, pero no se predice la fertilidad real (in vivo) de la muestra. La prueba de laboratorio ideal para estimar la calidad del semen in vitro tendría que cumplir con los requisitos de objetividad, repetibilidad, precisión, rapidez, sencillez y bajo costo (Soler et al., 2017).

En la valoración de la calidad seminal intervienen factores de tipo intrínseco, que son los que dependen del macho donador de semen como, por ejemplo, la edad (Knecht et al., 2017), raza (Smital et al., 2004), factores 
genéticos (Lavara et al., 2013) y las patologías (Lopez-Rodriguez et al., 2017), que pueden afectar la calidad del semen. Los factores extrínsecos como las condiciones medioambientales o factores relativos al manejo de los animales o del semen, afectan la calidad seminal (Guillette et al., 1999). Dentro de las condiciones medioambientales, la temperatura (Waberski et al., 2008) y el fotoperiodo (Knecht et al., 2013) son fuentes de variación importantes. Como factores de manejo de los animales, la alimentación (Surai \& Fisinin, 2015), la limpieza de las instalaciones o la forma de realizar la extracción de semen, pueden influir en la cantidad y calidad (funcional y microbiológica) del semen obtenido (Maroto-Martín et al., 2010). Por otra parte, la frecuencia de extracciones (Frangež et al., 2005) es un factor que también influye sobre la calidad seminal. Además, hay factores relativos al manejo del semen y producción de dosis seminales que son importantes en la calidad del producto final. El manejo en el laboratorio referido a la temperatura del material en contacto con el semen, contacto con el agua, la calibración de los equipos, la forma de realizar las diluciones, los medios de dilución utilizados (Valverde et al., 2019a), la temperatura, la duración del almacenamiento, el tipo de cámara de recuento utilizada (Valverde \& Madrigal-Valverde, 2019) y la higiene posterior a la extracción, son determinantes de la calidad de las dosis seminales producidas (Knox, 2016).

\section{Métodos para evaluar la calidad seminal}

\section{Espermiograma clásico}

Dentro del espermiograma clásico se incluyen pruebas macroscópicas y microscópicas sencillas que pueden realizarse sin necesidad de equipos de laboratorio muy sofisticados. En el Cuadro 1 se muestra la nomenclatura que se utiliza en los análisis de semen en función de la calidad que presentan los eyaculados para parámetros andrológicos (Ax et al., 2016).

Cuadro 1. Nomenclatura de los análisis de semen (Ax et al., 2016).

Table 1. Semen analysis nomenclature (Ax et al., 2016).

\begin{tabular}{ll}
\hline Parámetro y criterio de evaluación & Nomenclatura \\
\hline Volumen & \\
\hline Nada & Aspermia \\
Reducido & Hipospermia \\
Incrementado & Hiperespermia \\
\hline Concentración & \\
\hline Cero & Azoospermia \\
Reducida & Oligozoospermia \\
Normal & Normozoospermia \\
Incrementada & Polizoospermia \\
\hline Movilidad reducida & Astenozoospermia \\
\hline Viabilidad: todos muertos & Necrozoospermia \\
\hline Espermatozoides anormales: alto porcentaje & Teratozoospermia \\
\hline
\end{tabular}

En la evaluación macroscópica se realiza una primera observación de la apariencia general (consistencia y olor) y el volumen del eyaculado (Rozeboom, 2000). Los eyaculados son de color blanco nacarado (Park, 2013) y 
en muchas especies, excepto el conejo, la opacidad del eyaculado es proporcional a la concentración espermática. Las coloraciones amarillentas indican presencia de orina y el rosado presencia de sangre. No obstante, el semen de algunas especies como, por ejemplo, el toro, puede tener una tonalidad amarillenta por la presencia de riboflavina (Kodentsova et al., 2003), la cual no debe confundirse con presencia de orina. El volumen se debe medir con probetas graduadas o se puede pesar y se indica en $\mathrm{ml} \mathrm{o} \mu \mathrm{l}$ según la especie. El volumen y la concentración se utilizan para estimar el número de dosis seminales que pueden obtenerse de un eyaculado (Knecht et al., 2017).

Dentro de las pruebas microscópicas se incluyen la concentración (Kuster, 2005), la movilidad (Cummins, 2009), las morfoanomalías (Soler et al., 2000) y el estado del acrosoma (Tsujii et al., 2006). La concentración es el número de espermatozoides por unidad de volumen $(\mathrm{ml})$ que hay en el eyaculado y se mide con cámaras de recuento celular (Valverde \& Madrigal-Valverde, 2019). Al realizar el producto del volumen por la concentración se obtiene el número total de espermatozoides en el eyaculado, con este valor y en función de la concentración, a la que se preparen las dosis seminales, se puede estimar el número de dosis potenciales obtenidas de un eyaculado (Knox, 2016). Cuando se preparan las dosis seminales, en función del número total de espermatozoides móviles, se debe corregir por el porcentaje de movilidad total.

La movilidad de los espermatozoides es el parámetro más utilizado en la evaluación del semen (Yániz et al., 2018). La movilidad es necesaria para el transporte de los espermatozoides en el sistema reproductivo de la hembra y para atravesar todas las cubiertas del ovocito (Cummins, 2009). La correlación con la fertilidad no está del todo clara, porque este parámetro es multifactorial, sin embargo, en porcinos se ha observado que si las muestras presentan un porcentaje de espermatozoides móviles totales inferior al $70 \%$, tanto la fertilidad como la prolificidad (Ribeiro et al., 2008) pueden verse afectadas. La movilidad puede evaluarse por métodos subjetivos y poco fiables o por métodos objetivos, mediante los sistemas CASA (Yániz et al., 2018). El análisis subjetivo de la movilidad considera la movilidad masal (Clemente-Sánchez et al., 2015), que se evalúa en semen no diluido y se valora el número, la densidad y la velocidad del movimiento de las ondas o remolinos que se forman en la superficie de la gota de semen. Cuando no se ven ondas y los espermatozoides no se mueven se asigna un valor cero (categoría inferior), se van asignando valores hasta el valor más elevado (categoría 5, según la escala), donde se observan ondas densas y con movimiento muy rápido. Esta valoración se ha utilizado en especies con concentraciones espermáticas muy elevadas, aunque cada vez más va perdiendo validez. En la movilidad subjetiva individual, se parte del semen diluido y se valora la calidad y cantidad de movimiento. Se debe considerar que esta variable depende de la temperatura, por lo que es necesario evaluar las muestras a 37-38 ${ }^{\circ} \mathrm{C}$ para obtener una mejor estimación. Se puede indicar un porcentaje estimado de espermatozoides móviles totales y móviles con desplazamiento rectilíneo de la muestra o se puede proponer escalas. La escala (1-4) considera la puntuación más baja en muestras con movilidad muy reducida y la más alta se corresponde con las muestras que presentan muchos espermatozoides móviles y con desplazamiento rápido (Brinsko et al., 2011). Los eyaculados aptos deberían presentar más del $75 \%$ de espermatozoides móviles y al menos $65 \%$ de espermatozoides con movimiento progresivo (Kaysen et al., 2013).

\section{Análisis objetivo de la movilidad}

Los sistemas CASA constituyen una herramienta para la valoración objetiva de la movilidad espermática y otras variables del análisis de semen (Gallagher et al., 2018; Yániz et al., 2018). En estos sistemas, el microscopio se conecta a un ordenador y se capturan imágenes por unidad de tiempo a través de una cámara, las cuales se analizan posteriormente con un programa informático (Amann \& Katz, 2004). Para el análisis de la movilidad, el programa toma un punto de referencia para cada célula, por ejemplo, el centro de la cabeza o centroide, este punto se sigue a través de una secuencia de imágenes (Krause, 1995). El programa busca en la imagen consecutiva la cabeza del espermatozoide dentro de una zona de probabilidad, que es un círculo de un radio determinado alrededor 
de la cabeza. Este radio o zona de probabilidad se fija en función de la distancia máxima que se espera que un espermatozoide se desplace en ese periodo y es específico de cada especie (Boryshpolets et al., 2013).

Después de analizar las imágenes, el programa estima el porcentaje de espermatozoides móviles totales, móviles progresivos, porcentaje de espermatozoides estáticos, lentos, medios o rápidos, de acuerdo con los criterios de la Organización Mundial de la Salud (OMS) (Word Health Organization, 2016). Además, el programa también proporciona una serie de datos de velocidad, ratios, parámetros que aportan información respecto de la amplitud o de la frecuencia de batida del flagelo, que pueden ser indicadores de la movilidad hiperactivada (Mortimer et al., 2015). En la Figura 1 se presentan las principales variables de cinética espermática.
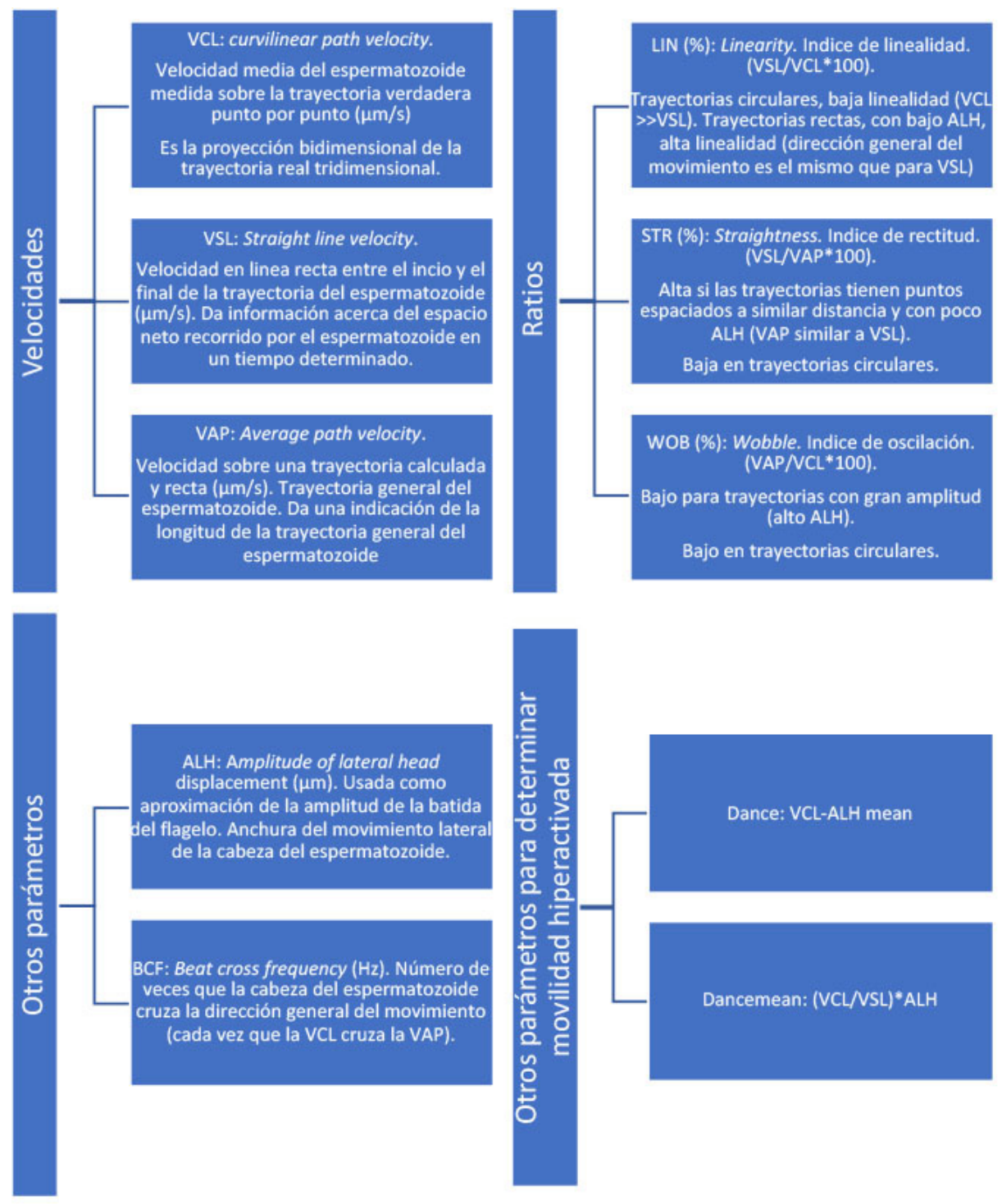

Figura 1. Resumen de las variables proporcionados por los sistemas CASA-Mot. Recuperado de Bompart et al. (2018).

Figure 1. Summary of the variables provided by the CASA-Mot systems. Retrieved from Bompart et al. (2018). 
Los sistemas CASA también presentan algunas limitaciones respecto de las estimaciones de las trayectorias (Bompart et al., 2018). Puede haber confusión de trayectorias cruzadas cuando la muestra presenta una alta concentración de espermatozoides o partículas de tamaño similar a la cabeza, que se confundan con espermatozoides estáticos (van der Horst et al., 2018). En el caso de especies con cabezas filiformes como el gallo y debido a que el sistema utiliza la cabeza como punto de referencia, se presentan problemas con la anchura del flagelo, ya que la cabeza es muy similar a esta estructura (García-Herreros, 2016). Los resultados obtenidos para una misma muestra, pueden ser diferentes en función del instrumento CASA utilizado (Ehlers et al., 2011), ya que algunos parámetros necesarios para la identificación de la cabeza, o la región de la cabeza que utilizan para reconstruir las trayectorias o los algoritmos empleados, son diferentes entre sistemas (van der Horst et al., 2018). Además, para poder comparar los resultados entre laboratorios, incluso cuando se utilizan sistemas idénticos, es necesario estandarizar las condiciones de trabajo entre los laboratorios, ya que los resultados obtenidos pueden variar en función del diluyente utilizado, la temperatura de captura, la cámara de recuento (Valverde \& Madrigal-Valverde, 2019), la tasa de fotogramas o frame rate (Castellini et al., 2011; Valverde et al., 2019a) y la dilución de la muestra (Soler et al., 2017).

Actualmente, se discute sobre la forma en que se estructura el eyaculado y como intervienen los diferentes conjuntos celulares que lo conforman, más que el estado global de la muestra seminal (García-Molina et al., 2019). La estructura subpoblacional del eyaculado en términos de la movilidad y cinética, hace que se conformen diversos conjuntos celulares con velocidades y progresividades altas, bajas e intermedias (Ramón \& Martínez-Pastor, 2018; Valverde et al., 2019b).

Algunas subpoblaciones presentan características de movilidad similares a las de espermatozoides capacitados o hiperactivados (Ramió et al., 2008). La información aportada por los sistemas CASA-Mot, permite conocer cómo se modifican los patrones del movimiento en función del tratamiento al que son sometidos los espermatozoides. Los tratamientos capacitantes modifican el patrón de movilidad, debido a que aumentará el número de espermatozoides hiperactivados (altos valores de ALH y VCL y baja LIN) y disminuirá el número de espermatozoides no hiperactivados que se reflejan en trayectorias relativamente regulares con baja ALH (García-Molina et al., 2019).

Los estudios futuros de la distribución de subpoblaciones en los eyaculados, deberían considerar diferentes enfoques con respecto a las especies y/o razas (líneas genéticas seleccionadas), la fuente de las muestras (epidídimo, semen en plasma seminal, espermatozoides diluidos en diluyentes comerciales, sexados o seleccionados por gradientes), el tipo de almacenamiento (enfriado o criopreservado) y aplicación (vaginal, sonda de inseminación intra-cervical, post-cervical o intrauterina). Se podrán presentar posibles patrones de subpoblación e interacción que aportarán otros significados en cada uno de estos contextos, por lo que la investigación debería orientarse a estudiar estos escenarios (Valverde et al., 2016; 2019c; 2019d; Víquez et al., 2020).

\section{Conclusiones}

La fertilidad es el parámetro que determina el éxito reproductivo tanto del macho como de la hembra y es el criterio económico que rentabiliza la actividad porcina en cualquier explotación.

El manejo de conceptos de biotecnología aplicada al semen en granja, tales como concentración, movilidad total y progresiva, así como el tipo de sonda utilizada de IA, permite disponer de dosis seminales con una calidad espermática óptima para su utilización en esquemas de inseminación artificial.

El uso de sistemas CASA ha representado una mejora en la estimación de las variables espermáticas y ha permitido optimizar el valor de los eyaculados por macho, a la vez que ha permitido un mayor conocimiento de la dinámica biológica de las subpoblaciones espermáticas en los eyaculados, descartando la idea de este como una unidad global. 


\section{Agradecimientos}

Los autores agradecen a la Fundación para el Fomento y la Promoción de la Investigación y Transferencia de Tecnología Agropecuaria (FITTACORI) y el Programa de Innovación y Transferencia de Tecnología (PITTAcerdos) del Ministerio de Agricultura y Ganadería de Costa Rica por el apoyo; también, se agradece el aporte de germoplasma seminal al Programa de Producción Agropecuaria (PPA) de la Escuela de Agronomía del Instituto Tecnológico de Costa Rica.

\section{Referencias}

Althouse, G., Kuster, C., Clark, S., \& Weisiger, R. (2000). Field investigations of bacterial contaminants and their effects on extended porcine semen. Theriogenology, 53(5), 1167-1176. https://doi.org/10.1016/S0093-691X(00)00261-2

Althouse, G., \& Lu, K. G. (2005). Bacteriospermia in extended porcine semen. Theriogenology, 63(2 SPEC. ISS.), $573-584$. https://doi.org/10.1016/j.theriogenology.2004.09.031

Amann, R., \& Katz, D. F. (2004). Andrology Lab Corner*: Reflections on CASA after 25 years. Journal of Andrology, 25(3), 317-325. https://doi.org/10.1002/j.1939-4640.2004.tb02793.x

Amann, R., \& Waberski, D. (2014). Computer-assisted sperm analysis (CASA): Capabilities and potential developments. Theriogenology, 81(1), 5-17.e3. https://doi.org/10.1016/J.THERIOGENOLOGY.2013.09.004

Aneas, S. B., Gary, B. G., \& Bouvier, B. P. (2008). Collectis® automated boar collection technology. Theriogenology, 70(8), 1368-1373. https://doi.org/10.1016/j.theriogenology.2008.07.011

Audet, I., Laforest, J. P., Martineau, G. P., \& Matte, J. J. (2004). Effect of vitamin supplements on some aspects of performance, vitamin status, and semen quality in boars. Journal of Animal Science, 82(2), 626-633. https://doi. org/10.2527/2004.822626x

Awda, B. J., \& Buhr, M. M. (2008). The effect of glove type on boar semen quality. Theriogenology, 70(8), 1388. https://doi. org/10.1016/j.theriogenology.2008.06.046

Ax, R. L., Dally, M., Didion, B. A., Lenz, R. W., Love, C. C., Varner, D. D., Hafez, B., \& Bellin, M. E. (2016). Semen evaluation. In B. Hafez \& E. Hafez (Eds.), Reproduction in farm animals (pp. 363-375). Lippincott Williams \& Wilkins. https:// doi.org/10.1002/9781119265306.ch25

Banaszewska, D., \& Kondracki, S. (2012). An assessment of the breeding maturity of insemination boars based on ejaculate quality changes. Folia Biologica, 60(3), 151-162. https://doi.org/10.3409/fb60_34.151162

Björndahl, L., \& Kvist, U. (2009). Human sperm chromatin stabilization: A proposed model including zinc bridges. Molecular Human Reproduction, 16(1), pp. 23-29. https://doi.org/10.1093/molehr/gap099

Bompart, D., García-Molina, A., Valverde, A., Caldeira, C., Yániz, J., Núñez de Murga, M., \& Soler, C. (2018). CASAMot technology: how results are affected by the frame rate and counting chamber. Reproduction, Fertility and Development, 30(6), 810-819. https://doi.org/10.1071/RD17551

Bonet, S., Casas, I., Holt, W., \& Yeste, M. (2013). Boar reproduction : fundamentals and new biotechnological trends. In S. Bonet, I. Casas, W. V. Holt, \& M. Yeste (Eds.), Boar Reproduction (1st ed., p. 632). Springer-Verlag Berlin Heidelberg. 
Boryshpolets, S., Kowalski, R. K., Dietrich, G. J., Dzyuba, B., \& Ciereszko, A. (2013). Different computer-assisted sperm analysis (CASA) systems highly influence sperm motility parameters. Theriogenology, 80(7), 758-765. https://doi. org/10.1016/j.theriogenology.2013.06.019

Brinsko, S. P., Blanchard, T. L., Varner, D. D., Schumacher, J., Love, C. C., Hinrichs, K., \& Hartman, D. L. (2011). Examination of the stallion for breeding soundness. In S. P. Brinsko, T. L. Blanchard, D. D. Varner, J. Schumacher, \& C. C. Love (Eds.), Manual of Equine Reproduction (pp. 176-206). Elsevier. https://doi.org/10.1016/b978-0-323-06482-8.00022-3

Britt, J., Almond, G., \& Flowers, W. (1999). Diseases of the reproductive system. In B. Straw, S. D’Allaire, W. Mengeling, \& D. Taylor (Eds.), Diseases of Swine (8th Ed., p. 905). Blackwell Science Ltd.

Broekhuijse, M. L. W. J., Šoštarić, E., Feitsma, H., \& Gadella, B. M. (2012). Application of computer-assisted semen analysis to explain variations in pig fertility. Journal of Animal Science, 90(3), 779-789. https://doi.org/10.2527/jas.2011-4311

Buhr, M. M., Fiser, P., Bailey, J. L., \& Curtis, E. F. (2001). Cryopreservation in different concentrations of glycerol alters boar sperm and their membranes. Journal of Andrology, 22(6), 961-969. https://doi.org/10.1002/j.1939-4640.2001.tb03436.x

Castellini, C., Dal Bosco, A., Ruggeri, S., \& Collodel, G. (2011). What is the best frame rate for evaluation of sperm motility in different species by computer-assisted sperm analysis? Fertility and Sterility, 96(1), 24-27. https://doi.org/10.1016/j. fertnstert.2011.04.096

Clemente-Sánchez, F., Cessa-Reyes, V., Cortez-Romero, C., Tarango-Arambula, L. A., \& Arenas-Baez, P. (2015). Commercial extenders and freezing curves for the preservation of sperm cells of white-tailed deer (Odocoileus virginianus). Journal of Applied Animal Research, 43(4), 468-473. https://doi.org/10.1080/09712119.2014.980422

Clements, K. M., Shipley, C. F., Coleman, D. A., Ehrhart, E. J., Haschek, W. M., \& Clark, S. G. (2010). Azoospermia in an 8-month-old boar due to bilateral obstruction at the testis/epididymis interface. The Canadian Veterinary Journal = La Revue Veterinaire Canadienne, 51(10), 1130-1134. http://www.ncbi.nlm.nih.gov/pubmed/21197205

Colagar, A. H., Marzony, E. T., \& Chaichi, M. J. (2009). Zinc levels in seminal plasma are associated with sperm quality in fertile and infertile men. Nutrition Research, 29(2), 82-88. https://doi.org/10.1016/j.nutres.2008.11.007

Cummins, J. (2009). Sperm motility and energetics. In T. Birkhead, D. Hosken, \& S. Pitnick (Eds.), Sperm biology, An evolutionary perspective (pp. 185-206). Academic Press.

Davies, D. C., Hall, G., Hibbitt, K. G., \& Moore, H. D. M. (1975). The removal of the seminal vesicles from the boar and the effects on the semen characteristics. Journal of Reproduction and Fertility, 43(2), 305-312. https://doi.org/10.1530/jrf.0.0430305

de Catanzaro, D., \& Pollock, T. (2016). Absorption and distribution of estradiol from male seminal emissions during mating. Journal of Endocrinology, 231(3), 245-257. https://doi.org/10.1530/JOE-16-0247

Ehlers, J., Behr, M., Bollwein, H., Beyerbach, M., \& Waberski, D. (2011). Standardization of computer-assisted semen analysis using an e-learning application. Theriogenology, 76(3), 448-454. https://doi.org/10.1016/j.theriogenology.2011.02.021

Estienne, M. J., \& Harper, A. F. (2004). Semen characteristics and libido in boars treated repeatedly with PGF $2 \alpha$. Journal of Animal Science, 82(5), 1494-1498. https://doi.org/10.2527/2004.8251494x

Flowers, W. (2015). Factors affecting the efficient production of boar sperm. Reproduction in Domestic Animals, 50, $25-30$. https://doi.org/10.1111/rda.12529

Flowers, W. L. (1997). Management of boars for efficient semen production. Journal of Reproduction and Fertility. Supplement, 52, 67-78. http://www.ncbi.nlm.nih.gov/pubmed/9602720 ISSN 2215-3608 doi:10.15517/am.v32i2.40628 
Frangež, R., Gider, T., \& Kosec, M. (2005). Frequency of boar ejaculate collection and its influence on semen quality, pregnancy rate and litter size. Acta Veterinaria (Brno), 74(2), 265-273. https://doi.org/10.2754/avb200574020265

Gallagher, M. T., Smith, D. J., \& Kirkman-Brown, J. C. (2018). CASA: tracking the past and plotting the future. Reproduction, Fertility and Development, 30(6), 867-874. https://doi.org/10.1071/RD17420

García-Herreros, M. (2016). Sperm subpopulations in avian species: a comparative study between the rooster (Gallus domesticus) and Guinea fowl (Numida meleagris). Asian Journal of Andrology, 18(6), 889-894. https://doi. org/10.4103/1008-682X.188448

García-Molina, A., Valverde, A., Bompart, D., Caldeira, C., Vendrell, A., \& Soler, C. (2019). Updating semen analysis: a subpopulation approach. Asian Journal of Andrology, 22(1), 118-119. https://doi.org/10.4103/aja.aja_33_19

Gogol, P., Szczesniak-Fabiańczyk, B., \& Wierzchoś-Hilczer, A. (2009). The photon emission, ATP level and motility of boar spermatozoa during liquid storage. Reproductive Biology, 9(1), 39-49. https://doi.org/10.1016/S1642-431X(12)60093-X

Goldberg, A., Argenti, L. E., Faccin, J. E., Linck, L., Santi, M., Lourdes Bernardi, M., Cardoso, M. R., Wentz, I., \& Bortolozzo, F. P. (2013). Risk factors for bacterial contamination during boar semen collection. Research in Veterinary Science, 95, 362-367. https://doi.org/10.1016/j.rvsc.2013.06.022

Guillette, J. L. J., Brock, J. W., Rooney, A. A., \& Woodward, A. R. (1999). Serum concentrations of various environmental contaminants and their relationship to sex steroid concentrations and phallus size in juvenile american alligators. Archives of Environmental Contamination and Toxicology, 36(4), 447-455. https://doi.org/10.1007/PL00006617

Guthrie, H. D., Welch, G. R., \& Long, J. A. (2008). Mitochondrial function and reactive oxygen species action in relation to boar motility. Theriogenology, 70(8), 1209-1215. https://doi.org/10.1016/j.theriogenology.2008.06.017

Herrick, J. (1950). Artificial insemination of swine. Iowa State University Veterinarian. https://lib.dr.iastate.edu/iowastate_ veterinarian/vol12/iss $1 / 4$

Hess, K. C., Jones, B. H., Marquez, B., Chen, Y., Ord, T. S., Kamenetsky, M., Miyamoto, C., Zippin, J. H., Kopf, G. S., Suarez, S. S., Levin, L. R., Williams, C. J., Buck, J., \& Moss, S. B. (2005). The "soluble" adenylyl cyclase in sperm mediates multiple signaling events required for fertilization. Developmental Cell, 9(2), 249-259. https://doi.org/10.1016/j. devcel.2005.06.007

Houška, L., Wolfová, M., \& Fiedler, J. (2004). Economic weights for production and reproduction traits of pigs in the Czech Republic. Livestock Production Science, 85(2-3), 209-221. https://doi.org/10.1016/S0301-6226(03)00128-3

Jiménez-Rabadán, P., Ramón, M., García-Álvarez, O., Maroto-Morales, A., del Olmo, E., Pérez-Guzmán, M. D., Bisbal, A., Fernández-Santos, M. R., Garde, J. J., \& Soler, A. (2012). Effect of semen collection method (artificial vagina vs. electroejaculation), extender and centrifugation on post-thaw sperm quality of Blanca-Celtibérica buck ejaculates. Animal Reproduction Science, 132(1-2), 88-95. https://doi.org/10.1016/j.anireprosci.2012.04.005

Johnson, L. A., Weitze, K. F., Fiser, P., \& Maxwell, W. M. (2000). Storage of boar semen. Animal Reproduction Science, 62(1-3), 143-172. http://www.ncbi.nlm.nih.gov/pubmed/10924823

Jones, A. R., \& Bubb, W. A. (2000). Substrates for endogenous metabolism by mature boar spermatozoa. Journal of Reproduction and Fertility, 119(1), 129-135. https://doi.org/10.1530/reprod/119.1.129

Kaysen, B. L., Levalley, S. B., Ames, D. R., Dalsted, N. L., Schwab, C. R., Daryl, J., Cleon, T., \& Kimberling, V. (2013). Dissertation factors that impact probability of pregnancy when using ai boars. Colorado State University. 
Knecht, D., Jankowska-Mąkosa, A., \& Duziński, K. (2017). The effect of age, interval collection and season on selected semen parameters and prediction of AI boars productivity. Livestock Science, 201, 13-21. https://doi.org/10.1016/j. livsci.2017.04.013

Knecht, D., Środoń, S., Szulc, K., \& Duziński, K. (2013). The effect of photoperiod on selected parameters of boar semen. Livestock Science, 157(1), 364-371. https://doi.org/10.1016/j.livsci.2013.06.027

Knox, R. V. (2016). Artificial insemination in pigs today. Theriogenology, 85(1), 83-93. https://doi.org/10.1016/j. theriogenology.2015.07.009

Ko, J. C. H., Evans, L. E., \& Althouse, G. (1989). Toxicity effects of latex gloves on boar spermatozoa. Theriogenology, 31(6), 1159-1164. https://doi.org/10.1016/0093-691X(89)90084-8

Kodentsova, V. M., Vrzhesinskaya, O. A., \& Evdokimov, V. V. (2003). Riboflavin content in male spermoplasm. Bulletin of Experimental Biology and Medicine, 135(3), 258-260. https://doi.org/10.1023/A:1024184914560

Kondracki, S., Iwanina, M., Wysokińska, A., \& Huszno, M. (2012). Comparative analysis of Duroc and Pietrain boar sperm morphology. Acta Veterinaria Brno, 81(2), 195-199. https://doi.org/10.2754/avb201281020195

Krause, W. (1995). Computer-assisted semen analysis systems: comparison with routine evaluation and prognostic value in male fertility and assisted reproduction. Human Reproduction, 10(Suppl. 1), 60-66. http://www.ncbi.nlm.nih.gov/ pubmed/8592042

Kumaresan, A., Kadirvel, G., Bujarbaruah, K. M., Bardoloi, R. K., Das, A., Kumar, S., \& Naskar, S. (2009). Preservation of boar semen at $18{ }^{\circ} \mathrm{C}$ induces lipid peroxidation and apoptosis like changes in spermatozoa. Animal Reproduction Science, 110(1-2), 162-171. https://doi.org/10.1016/j.anireprosci.2008.01.006

Kuster, C. (2005). Sperm concentration determination between hemacytometric and CASA systems: Why they can be different. Theriogenology, 64(3), 614-617. https://doi.org/10.1016/J.THERIOGENOLOGY.2005.05.047

Lavara, R., Vicente, J. S., \& Baselga, M. (2013). Genetic variation in head morphometry of rabbit sperm. Theriogenology, 80(4), 313-318. https://doi.org/10.1016/J.THERIOGENOLOGY.2013.04.015

Ledesma, A., Zalazar, L., Fernández-Alegre, E., Hozbor, F., Cesari, A., \& Martínez-Pastor, F. (2017). Seminal plasma proteins modify the distribution of sperm subpopulations in cryopreserved semen of rams with lesser fertility. Animal Reproduction Science, 184, 44-50. https://doi.org/10.1016/j.anireprosci.2017.06.015

Lelono, A., Riedstra, B., \& Groothuis, T. (2019). Ejaculate testosterone levels affect maternal investment in red junglefowl (Gallus gallus gallus). Scientific Reports, 9(1), Article 12126. https://doi.org/10.1038/s41598-019-48563-W

Leonhard-Marek, S. (2001). Influence of drugs, pollution and trace elements on male fertility. In W. Busch, \& A. Holzmann (Eds.), Andrology in veterinary medicine (pp. 474-481). Schattauer.

Levis, D. G., \& Reicks, D. L. (2005). Assessment of sexual behavior and effect of semen collection pen design and sexual stimulation of boars on behavior and sperm output - A review. Theriogenology, 63(2 SPEC. ISS.), 630-642. https:// doi.org/10.1016/j.theriogenology.2004.09.037

Li, X., Wang, L., Li, Y., Zhao, N., Zhen, L., Fu, J., \& Yang, Q. (2016). Calcium regulates motility and protein phosphorylation by changing cAMP and ATP concentrations in boar sperm in vitro. Animal Reproduction Science, 172, 39-51. https:// doi.org/10.1016/j.anireprosci.2016.07.001

Lopez-Rodriguez, A., Soom, A. Van, Arsenakis, I., \& Maes, D. (2017). Boar management and semen handling factors affect the quality of boar extended semen. Porcine Health Management, 3, Article 15. https://doi.org/10.1186/s40813-017-0062-5 
López Rodríguez, A., Rijsselaere, T., Beek, J., Vyt, P., Van Soom, A., \& Maes, D. (2013). Boar seminal plasma components and their relation with semen quality. Systems Biology in Reproductive Medicine, 59(1), 5-12. https://doi.org/10.3109/19 396368.2012 .725120

Maes, D., López Rodríguez, Alfonso Rijsselaere, T., Vyt, P., \& Van Soom, A. (2011). Artificial Insemination in Pigs. In E. Manafi (Ed.), Artificial insemination in farm animals (pp. 79-94). In Tech.

Marin-Guzman, J., Mahan, D. C., \& Whitmoyer, R. (2000). Effect of dietary selenium and vitamin E on the ultrastructure and ATP concentration of boar spermatozoa, and the efficacy of added sodium selenite in extended semen on sperm motility. Journal of Animal Science, 78(6), 1544-1550. https://doi.org/10.2527/2000.7861544x

Maroto-Martín, L. O., Muñoz, E. C., De Cupere, F., Van Driessche, E., Echemendia-Blanco, D., Rodríguez, J. M. M., \& Beeckmans, S. (2010). Bacterial contamination of boar semen affects the litter size. Animal Reproduction Science, 120(1-4), 95-104. https://doi.org/10.1016/j.anireprosci.2010.03.008

Martinez-Alborcia, M. J., Valverde, A., Parrilla, I., Vazquez, J. M., Martinez, E. A., \& Roca, J. (2012). Detrimental effects of non-functional spermatozoa on the freezability of functional spermatozoa from Boar Ejaculate. PLoS ONE, 7(5), Article e36550. https://doi.org/10.1371/journal.pone.0036550

Massányi, P., Trandzik, J., Nad, P., Toman, R., Skalická, M., \& Koréneková, B. (2003). Seminal concentrations of trace elements in various animals and their correlations. Asian Journal of Andrology, 5(2), 101-104. http://www.ncbi.nlm.nih.gov/ pubmed/12778318

McPherson, F. J., Nielsen, S. G., \& Chenoweth, P. J. (2014). Semen effects on insemination outcomes in sows. Animal Reproduction Science, 151(1-2), 28-33. https://doi.org/10.1016/J.ANIREPROSCI.2014.09.021

Medrano, A., Fernández-Novell, J. M., Ramió, L., Alvarez, J., Goldberg, E., Rivera, M. M., Guinovart, J. J., Rigau, T., \& Rodríguez-Gil, J. E. (2006). Utilization of citrate and lactate through a lactate dehydrogenase and ATP-regulated pathway in boar spermatozoa. Molecular Reproduction and Development, 73(3), 369-378. https://doi.org/10.1002/ $\operatorname{mrd} .20414$

Mortimer, S. T., Van Der Horst, G., \& Mortimer, D. (2015). The future of computer-aided sperm analysis. Asian Journal of Andrology, 17(4), 545-553. https://doi.org/10.4103/1008-682X.154312

Murase, T., Imaeda, N., Yamada, H., \& Miyazawa, K. (2007). Seasonal changes in semen characteristics, composition of seminal plasma and frequency of acrosome reaction induced by calcium and calcium ionophore A23187 in large white boars. Journal of Reproduction and Development, 53(4), 853-865. https://doi.org/10.1262/jrd.19026

Naughton, C. K., Nelson, D. R., \& Thomas, A. J. (2003). Development of an Inexpensive Artificial Vagina for Semen Collection from Rabbits. Journal of Andrology, 24(5), 712-715. https://doi.org/10.1002/j.1939-4640.2003.tb02731.x

Okamura, N., Tajima, Y., Soejima, A., Masuda, H., \& Sugita, Y. (1985). Sodium bicarbonate in seminal plasma stimulates the motility of mammalian spermatozoa through direct activation of adenylate cyclase. The Journal of Biological Chemistry, 260(17), 9699-9705. http://www.ncbi.nlm.nih.gov/pubmed/2991260

Park, S. (2013). Effects of sow, boar, and semen traits on sow reproduction. University of Nebraska-Lincoln. https:// digitalcommons.unl.edu/animalscidiss/67

Pesch, S., Bergmann, M., \& Bostedt, H. (2006). Determination of some enzymes and macro- and microelements in stallion seminal plasma and their correlations to semen quality. Theriogenology, 66(2), 307-313. https://doi.org/10.1016/j. theriogenology.2005.11.015 
Pieczyńska, J., \& Grajeta, H. (2015). The role of selenium in human conception and pregnancy. Journal of Trace Elements in Medicine and Biology, 29, 31-38. https://doi.org/10.1016/j.jtemb.2014.07.003

Pipan, M. Z., Mrkun, J., Strajn, B. J., Vrtač, K. P., Kos, J., Pišlar, A., \& Zrimšek, P. (2017). The influence of macro- and microelements in seminal plasma on diluted boar sperm quality. Acta Veterinaria Scandinavica, 59(1), Article 11. https://doi.org/10.1186/s13028-017-0279-y

Pruneda, A., Pinart, E., Briz, M. D., Sancho, S., Garcia-Gil, N., Badia, E., Kadar, E., Bassols, J., Bussalleu, E., Yeste, M., \& Bonet., S. (2005). Effects of a high semen-collection frequency on the quality of sperm from ejaculates and from six epididymal regions in boars. Theriogenology, 63, 2219-2232. https://doi.org/10.1016/j.theriogenology.2004.10.009

Quirós-Rojas, M., Madrigal-Valverde, M., Camacho-Calvo, M., \& Valverde, A. (2018). Efecto del catéter de inseminación y el orden de parto sobre parámetros de producción en ganado porcino. Revista Tecnología En Marcha, 31(3), 86-97. https://doi.org/10.18845/tm.v31i3.3905

Ramió, L., Rivera, M. M., Ramírez, A., Concha, I. I., Peña, A., Rigau, T., \& Rodríguez-Gil, J. E. (2008). Dynamics of motilesperm subpopulation structure in boar ejaculates subjected to "in vitro" capacitation and further "in vitro" acrosome reaction. Theriogenology, 69(4), 501-512. https://doi.org/10.1016/j.theriogenology.2007.10.021

Ramón, M., \& Martínez-Pastor, F. (2018). Implementation of novel statistical procedures and other advanced approaches to improve analysis of CASA data. Reproduction, Fertility and Development, 30(6), 860-866. https://doi.org/10.1071/RD17479

Ratchamak, R., Vongpralub, T., Boonkum, W., \& Chankitisakul, V. (2019). Cryopreservation and quality assessment of boar semen collected from bulk samples. Veterinarni Medicina, 64(05), 209-216. https://doi.org/10.17221/125/2018VETMED

Ribeiro, J. C., Carvalho, L. E., Sousa, K. C., \& Nepomuceno, R. C. (2008). Prolificidade de fêmeas suínas na cidade de Fortaleza, Ceará, Brasil. Archivos de Zootecnia, 57(220), 537-540. http://www.redalyc.org/articulo.oa?id=49515034015

Robinson, J. A. B., \& Buhr, M. M. (2005). Impact of genetic selection on management of boar replacement. Theriogenology, 63(2), 668-678. https://doi.org/10.1016/j.theriogenology.2004.09.040

Rodríguez-Gil, J. E., \& Bonet, S. (2016). Current knowledge on boar sperm metabolism: Comparison with other mammalian species. Theriogenology, 85(1), 4-11. https://doi.org/10.1016/j.theriogenology.2015.05.005

Rodríguez-Martínez, H., Kvist, U., Ernerudh, J., Sanz, L., \& Calvete, J. J. (2011). Seminal plasma proteins: What role do they play? American Journal of Reproductive Immunology, 66(SUPPL. 1), 11-22. https://doi.org/10.1111/j.16000897.2011.01033.x

Rozeboom, K. (2000). Evaluating Boar Semen Quality (ANS 00-812S). North Carolina State University. https://projects.ncsu. edu/project/swine_extension/publications/factsheets/812s.htm

Sağlam, H. S., Altundağ, H., Atik, Y. T., Dündar, M. Ş., \& Adsan, Ö. (2015). Trace elements levels in the serum, urine, and semen of patients with infertility. Turkish Journal of Medical Sciences, 45(2), 443-448. https://doi.org/10.3906/sag-1402-140

Seligman, J., Newton, G. L., Fahey, R. C., Shalgi, R., \& Kosower, N. S. (2005). Nonprotein thiols and disulfides in rat epididymal spermatozoa and epididymal fluid: Role of $\gamma$-glutamyl-transpeptidase in sperm maturation. Journal of Andrology, 26(5), 629-637. https://doi.org/10.2164/jandrol.05040

Sepúlveda, L., Bussalleu, E., Yeste, M., \& Bonet, S. (2014). Effects of different concentrations of Pseudomonas aeruginosa on boar sperm quality. Animal Reproduction Science, 150(3-4), 96-106.https://doi.org/10.1016/j.anireprosci.2014.09.001 
Smital, J., Sousa, L. L. De, \& Mohsen, A. (2004). Differences among breeds and manifestation of heterosis in AI boar sperm output. Animal Reproduction Science, 80, 121-130. https://doi.org/10.1016/S0378-4320(03)00142-8

Smith, S. C., \& England, G. C. (2001). Effect of technical settings and semen handling upon motility characteristics of dog spermatozoa measured using computer-aided sperm analysis. Journal of Reproduction and Fertility. Supplement, 57, 151-159. http://www.ncbi.nlm.nih.gov/pubmed/11787144

Soler, C., Perez-Sanchez, F., Schulze, H., Bergmann, M., Oberpenning, F., Yeung, C.-H., \& Cooper, T. (2000). Objective evaluation of the morphology of human epididymal sperm heads. International Journal of Andrology, 23(2), 77-84. https://doi.org/10.1046/j.1365-2605.2000.00211.x

Soler, C., Valverde, A., Bompart, D., Fereidounfar, S., Sancho, M., Yániz, J., Garcia-Molina, A., \& Korneenko-Zhilyaev, Y. (2017). New methods of semen analysis by casa. Sel'skokhozyaistvennaya Biologiya (Agricultural Biology), 52(2), 232-241. https://doi.org/10.15389/agrobiology.2017.2.232eng

Strzežek, J., Korda, W., Glogowski, J., Wysocki, P., \& Borkowski, K. (1995). Influence of Semen-collection Frequency on Sperm Quality in Boars, with Special Reference to Biochemical Markers. Reproduction in Domestic Animals, 30(2), 85-94. https://doi.org/10.1111/j.1439-0531.1995.tb00609.x

Surai, P. F., \& Fisinin, V. I. (2015). Selenium in pig nutrition and reproduction: Boars and semen quality - A review. AsianAustralasian Journal of Animal Sciences, 28(5), 730-736. https://doi.org/10.5713/ajas.14.0593

Tejerina, F., Buranaamnuay, K., Saravia, F., Wallgren, M., \& Rodriguez-Martinez, H. (2008). Assessment of motility of ejaculated, liquid-stored boar spermatozoa using computerized instruments. Theriogenology, 69(9), 1129-1138. https://doi.org/10.1016/j.theriogenology.2008.01.027

Töpfer-Petersen, E., Romero, A., Varela, P. F., Ekhlasi-Hundrieser, M., Dostàlovà, Z., Sanz, L., \& Calvete, J. J. (2009). Spermadhesins: A new protein family. Facts, hypotheses and perspectives. Andrologia, 30(4-5), 217-224. https://doi. org/10.1111/j.1439-0272.1998.tb01163.x

Tosky, E., Dysart, N., Swing, S., \& Flowers, W. (2013). Libido, semen characteristics and fertility of boars housed in crates versus pens. Journal of Animal Science, 91(Suppl 2), 123.

Tourmente, M., \& Roldan, E. R. S. (2015). Mass-specific metabolic rate influences sperm performance through energy production in mammals. PLoS ONE, 10(9), Article e0138185. https://doi.org/10.1371/journal.pone.0138185

Tremoen, N. H., Gaustad, A. H., Andersen-Ranberg, I., van Son, M., Zeremichael, T. T., Frydenlund, K., Grindflek, E., Våge, D. I., \& Myromslien, F. D. (2018). Relationship between sperm motility characteristics and ATP concentrations, and association with fertility in two different pig breeds. Animal Reproduction Science, 193, 226-234. https://doi. org/10.1016/J.ANIREPROSCI.2018.04.075

Tsujii, H., Ohta, E., Miah, A. G., Hossain, S., \& Salma, U. (2006). Effect of fructose on motility, acrosome reaction and in vitro fertilization capability of boar spermatozoa. Reproductive Medicine and Biology, 5(4), 255-261. https://doi. org/10.1111/j.1447-0578.2006.00150.x

Turner, R. M. (2003). Tales from the Tail: What Do We Really Know about Sperm Motility? Journal of Andrology, 24(6), 790-803. https://doi.org/10.1002/j.1939-4640.2003.tb03123.x

Valverde, A., Areán, H., Fernández, A., Bompart, D., García-Molina, A., López-Viana, J., \& Soler, C. (2019a). Combined effect of type and capture area of counting chamber and diluent on Holstein bull sperm kinematics. Andrologia, 51(4), e13223. https://doi.org/10.1111/and.13223 
Valverde, A., Arenán, H., Sancho, M., Contell, J., Yániz, J., Fernández, A., \& Soler, C. (2016). Morphometry and subpopulation structure of Holstein bull spermatozoa: variations in ejaculates and cryopreservation straws. Asian Journal of Andrology, 18(6), 851-857. https://doi.org/10.4103/1008-682X.187579

Valverde, A., Castro-Morales, O., Madrigal-Valverde, M., \& Soler, C. (2019b). Sperm kinematics and morphometric subpopulations analysis with CASA systems: A review. Revista de Biologia Tropical, 67(6), 1473-1487. https://doi. org/10.15517/rbt.v67i6.35151

Valverde, A., \& Madrigal-Valverde, M. (2019). Evaluación de cámaras de recuento sobre parámetros espermáticos de verracos analizados con un sistema CASA-Mot. Agronomía Mesoamericana, 30(2), 447-458. https://doi.org/10.15517/ am.v30i1.34145

Valverde, A., Madrigal-Valverde, M., Caldeira, C., Bompart, D., Núñez de Murga, J., Arnau, S., \& Soler, C. (2019c). Effect of frame rate capture frequency on sperm kinematic parameters and subpopulation structure definition in boars, analyzed with a CASA-Mot system. Reproduction in Domestic Animals, 54(2), 167-175. https://doi.org/10.1111/rda.13320

Valverde, A., Madrigal-Valverde, M., Castro-Morales, O., Gadea-Rivas, A., Johnston, S., \& Soler, C. (2019d). Kinematic and head morphometric characterisation of spermatozoa from the Brown Caiman (Caiman crocodilus fuscus). Animal Reproduction Science, 207, 9-20. https://doi.org/10.1016/J.ANIREPROSCI.2019.06.011

Valverde, A., Madrigal-Valverde, M., Lotz, J., Bompart, D., \& Soler, C. (2019e). Effect of video capture time on sperm kinematic parameters in breeding boars. Livestock Science, 220, 52-56. https://doi.org/10.1016/j.livsci.2018.12.008

Valverde, A., Madrigal-Valverde, M., Solís-Arias, J., \& Paniagua-Madrigal, W. (2019f). Variabilidad en los métodos de estimación de la concentración espermática en verracos. Agronomía Costarricense, 43(2), 25-43. https://doi. org/10.15517/rac.v43i2.37793

van der Horst, G., Maree, L., \& du Plessis, S. (2018). Current perspectives of CASA applications in diverse mammalian spermatozoa. Reproduction, Fertility and Development, 30(6), 875-888. https://doi.org/10.1071/RD17468

Verstegen, J., Iguer-Ouada, M., \& Onclin, K. (2002). Computer assisted semen analyzers in andrology research and veterinary practice. Theriogenology, 57(1), 149-179. https://doi.org/10.1016/S0093-691X(01)00664-1

Víquez, L., Barquero, V., Soler, C., Roldan, E. R. S., \& Valverde, A. (2020). Kinematic sub-populations in bull spermatozoa: A Comparison of Classical and Bayesian Approaches. Biology, 9(6), Article 138. https://doi.org/10.3390/biology9060138

Waberski, D., Petrunkina, A. M., \& Töpfer-Petersen, E. (2008). Can external quality control improve pig AI efficiency? Theriogenology, 70(8), 1346-1351. https://doi.org/10.1016/j.theriogenology.2008.06.006

World Health Organization. (2016). WHO laboratory manual for the examination and processing of human semen. https://www. who.int/publications/i/item/9789241547789

Wu, A. S. H., Oldfield, J. E., Shull, L. R., \& Cheeke, P. R. (1979). Specific Effect of Selenium Deficiency on Rat Sperm1. Biology of Reproduction, 20(4), 793-798. https://doi.org/10.1095/biolreprod20.4.793

Yániz, J., Silvestre, M., Santolaria, P., \& Soler, C. (2018). CASA-Mot in mammals: an update. Reproduction, Fertility, and Development, 30(6), 799-809. https://doi.org/10.1071/RD17432

680 ISSN 2215-3608 doi:10.15517/am.v32i2.40628 